\title{
Kleider machen Leute
}

Erhard Taverna

* Unico swiss tex GmbH, Alpnachstad,info@hess-sattlerei.ch.
Ein beliebtes Thema jeder Erzählkunst war schon immer die Wirkung von Kleidern auf den Träger und ganz besonders auf die Reaktion seiner Mitmenschen. Die Wendung «Kleider machen Leute» gehört seit Gottfried Kellers gleichnamiger Novelle zu unserem Wortschatz. Doch seit die Leute der Textilbranche multifunktionale Gewebe entwickeln, hat für Seldwyla und den Rest der Welt ein völlig neuartiges Zeitalter begonnen. Schnittmuster und Nähnadel haben sich mit Chemie und Physik verbündet. Die Kataloge heutiger Textilmessen bieten eine Schau modernster Verbundwerkstoffe, vom Nanosilikat über thermoplastische Schäume zu neuen Harzen, Sol-Gel-aktivierten Polyamiden und bioaktiven Metallen. Technische Textilien haben alle Bereiche vom Laufsteg bis zum Operationssaal erobert. Sport, Militär und Medizin sind die treibenden Kräfte.

Von der Plastikeuphorie der 60er Jahre und dem bügelfreien Nylonhemd blieb im Kleiderschrank wenig übrig. Doch dann verdrängten Kunstfasern wie Polypropylen, Polyamid und Polyester oder Elastan die gute alte Baumwolle aus der Sportbekleidung, und die Aramidpolymere von DuPont begannen 1970 unter dem Namen Keflar ihren Siegeszug. Als ballistisches Gewebe sorgen die Fasern für kugelsichere Westen, sie schützen Feuerwehrleute, dienen als Bremsbeläge und verstärken das alte Segeltuch. Den atmungsaktiven Membranen wie Gore-Tex und Sympatex folgten spezielle UV-Filter für Lichtallergiker. Polyurethanfolien mit flexibler Luftdurchlässigkeit, muskelmassierende Laufstrümpfe und Silberionen gegen den mikrobiellen Schweissabbau beflügeln die Marathonläufer. Die neue Mode aus dem Labor ermöglicht Bikinis, die eine nahtlose Bräune garantieren oder adaptive Kleider, die Medikamente gegen Hautkrankheiten freisetzen. Eingewebte Garne mit winzigen Glasreflektoren reflektieren das Licht im Strassenverkehr, und Gewebe mit Mikrokapseln aus Paraffin wirken als regulierende Klimaanlage. High-Tech-Jacken mit integrierten Navigationssystemen, sprechende Socken und intelligente Hosen sind bereits Realität. Wir bewegen uns in Richtung der Tarnkappen und Siebenmeilenstiefel.

Aus der Forschungsabteilung der EMPA stammen Textilien mit vielfältigen chirurgischen und onkologischen Anwendungen. Beispiele sind Herniennetzimplantate und optische Kunststof- fasern für Lichtapplikationen in der lokalen photodynamischen Krebstherapie oder Funktionsmaterialien aus Laminaten, die den Körper kühlen. Im Januar wurden die besten Geschäftsideen des Businesswettbewerbs «Venture 2008» prämiert, darunter auch ein Projekt, an dem die EMPA massgeblich beteiligt war.

Die Firma Unico swiss tex $\mathrm{GMbH}^{*}$ in Alpnachstad, die das Patent von der EMPA erwarb, produziert ultraleichte Kühlbekleidungen, geeignet für Sportler oder MS-Patientinnen und -Patienten. Die aus mehreren Schichten bestehenden Jacken und Hosen werden je nach Typ mit 20-100 ml Wasser gefüllt, das auf der Aussenseite verdunstet. Damit lässt sich die Hauttemperatur für ein bis zwei Stunden um vier bis fünf Grad senken. Besonders MS-Patienten, die intensiv unter sommerlichen Temperaturen leiden, profitieren von diesen Anzügen, die problemlos unter wasserdampfdurchlässigen Kleidern getragen werden können. Die bekannten Hitzesymptome wie Spastik, Schmerzen, Erschöpfung und verminderte Muskelkraft gehen dabei stark zurück. Die sozialen Vorteile sind ein weiterer Fortschritt,
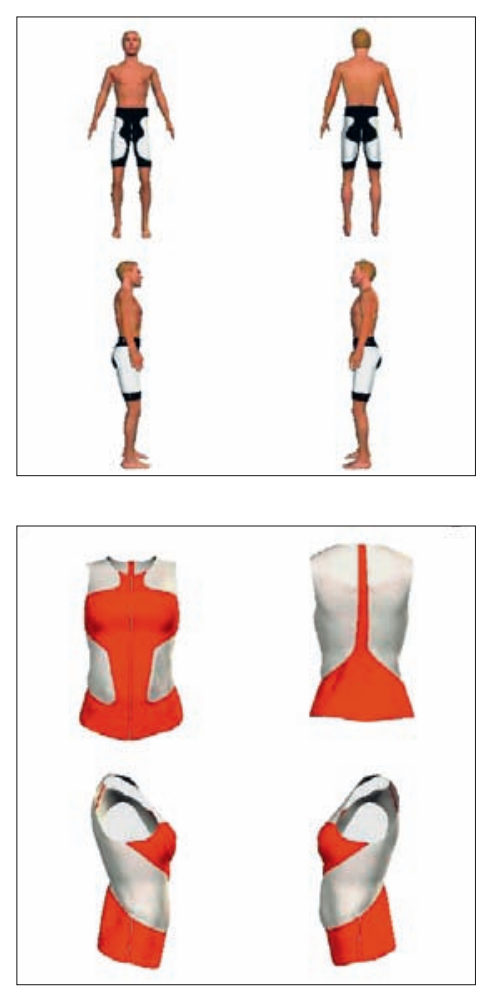
da Jacke und Hose angenehm zu tragen sind, sportlich aussehen und sensitiven MS-Patientinnen und -Patienten auch bei Wärme und schwülem Wetter einen befristeten Aufenthalt im Freien erlauben. Dass dieses Kühlsystem keine äussere Energie benötigt, ist ein weiteres Plus dieser Technologie. Billig sind diese nützlichen Klamotten nicht. Solange IV und Krankenkassen nicht zahlen, wäre es eine Aufgabe der MS-Liga, weniger bemittelten Patientinnen und Patienten auszuhelfen.

Die Mythologie geht der Technik voraus. Dem heldenhaften Herkules verbrannte ein Hemd elendiglich Haut und Fleisch, weil seine eifersüchtige Geliebte das Gewebe mit dem Blut eines von diesem getöteten Kentauren tränkte. Der sterbende Nessos rächte sich mit einer List, als er ihr anstelle der todbringenden Wirkung einen Liebeszauber vortäuschte.

Die Wissenschaft hat den alten Fluch in eine Heilkunst verwandelt. Die neuen Hemden kühlen den Träger und die Trägerin. Gegen Verrat und Eifersucht helfen sie allerdings (noch) nicht.

\section{Klänge in Moll und Dur}

\section{Kazem Mohtadi, Zofingen}

In berstender Nacht, im Abgrund, Mit Scham und Wut, im Herzen wund Erblick dein graues Haar, den Rückenbogen Verwehte Wünsche mit mir dein Vermögen. Hast dich lange meiner Geburt erfreut, Bei Erziehung keine Mühe gescheut. Doch bin ich im Drogennetz verfangen, Um ihre Knospen die Eltern bangen.

Jene plädieren schlicht für die Freigabe, Andere begrenzen den Schaden, erste Aufgabe. Dealer in Pracht, mächtige Fürsten, Erbärmliche Sklaven von bösen Lüsten. Keiner sieht wahr eine Helle, Kein Mittel taugt für alle Fälle.

Denn mich reisst's nach der Pumpe, Wenn ich stürze auch in die Sümpfe. Was redest du mir ins Gewissen? Ich bin aus allen Banden gerissen. Frag sie, ob sich das Leben wirklich lohne, Dem Mann bloss Leib und Unterleib innewohne. Ritterlichkeit ein obsoletes Wort, Fülle und wilde Gelüste der Hort. Als ob anderen nichts fehle, Dass er leert für mich die Kehle.
Und deine Selbstvorwürfe, Schuldgefühle, $\mathrm{Zu}$ lang verschwiegen, Wasser auf die Mühle. Mich nicht fortgejagt im grossen Kummer, Obgleich ich fort unverschämt dummer. Denkst das Ziel zu hoch gesteckt? Versagt, den Raster fehlgesetzt? Ich schaffe es nicht durch Zuwendung und Liebe, Eher gepaart damit Strenge und Lebenshiebe! Am liebsten bin aber verladen in der Ecke, Egal, ob ich und die ganze Welt verrecke! Besorgt, geleitet von Ratio und Gefühl Schallt aus Gasse und Arena ein Gebrüll.

Natürlich hoffe ich auf Dauerkonsum, Den Rausch unter Haschisch, Kokain und Opium. High im Fall von Freigabe, Dauer im Boom. Wer denkt an Abstinenz, weg vom Krumm? Keine Grenze kennen Menschentriebe, Ohne Schranke, Aufruhr im Getriebe! Mass setzen Natur und Kultur, Konventionen mit Blick auf Futur, Goldene Mitte die Richtschnur, Hallen Klänge in Moll und Dur: Verblasse das weisse Pulver! Entbräune der braune Zucker! Entrücke der Cannabis Dieser Schizokokkekabis 